\title{
POSITIVE EXPIRATORY PRESSURE PLATEAU: IMPROVED GAS EXCHANGE DURING MECHANICAL VENTILATION*
}

\author{
R. W. MCINTYRE, M.B., CH.B., D.A., F.R.C.P.(C), \\ A. K. LAWS, B.SC., M.B., B.S., F.F.A.R.C.S., \\ AND P. R. RAMAChaNDRAN, M.B., B.S., F.R.C.P.(c) $†$
}

IT IS WELL KNOwN that the pattern of mechanical ventilation can affect the efficiency of pulmonary gas exchange. Despite this, the optimum ventilatory wave form has yet to be defined. In the past, most research has pertained to the pattern of inspiration $^{1-4}$ and relatively little attention has been directed to the expiratory phase of ventilation. The concept of a maintained expiratory pressure as a means of improving gas exchange during mechanical ventilation is not new. Enthusiasm for the clinical use of maintained pressure during expiration has been tempered somewhat by Cournand's work, ${ }^{5}$ which predicts a fall in cardiac output because of the inevitable associated rise in mean inflating pressure. There are relevant reports from animal studies ${ }^{6,7}$ and from studies using anaesthetized human subjects. ${ }^{8-10}$ In these studies, methodology varies and the results are conflicting. More recently, however, several workers have ventilated critically ill patients using a maintained expiratory pressure and have shown improved oxygenation. ${ }^{11-13}$

It was the object of the present study to examine the effects of a Positive Expiratory Pressure Plateau (PEPP) on gas exchange, cardiac output, and functional residual capacity, and to define its place in the clinical management of patients receiving artificial ventilation. PEPP refers to a particular feature of the ventilatory wave form. Figure 1 is a tracing of airway pressure and shows the characteristic feature. A constant pressure is maintained throughout the expiratory phase, and airway pressure at no time returns to ambient pressure. This should be distinguished from an expiratory flow retard resulting from a restriction in the expiratory line.

\section{Methodology AND Design of Study}

The subjects for study were five patients in severe respiratory failure. The clinical details of these patients are recorded in Table I. All patients were on controlled ventilation with constant volume ventilators-the Ohio 560 or the Bennett Mal. Tidal volumes ranged from 8 to $14 \mathrm{ml} / \mathrm{kg}$ without intermittent sighs. All patients were ventilated with 100 per cent oxygen at the time the measurements were made. (Three patients required this level of inspired oxygen to maintain adequate oxygenation.)

On the Ohio 560, provision is made for applying PEPP. When the Bennett MAI

'Presented at the Annual Meeting, Canadian Anaesthetists' Society, Toronto, June 17, 1969.

†Department of Anaesthesia, University of Toronto, and the Toronto General Hospital. 


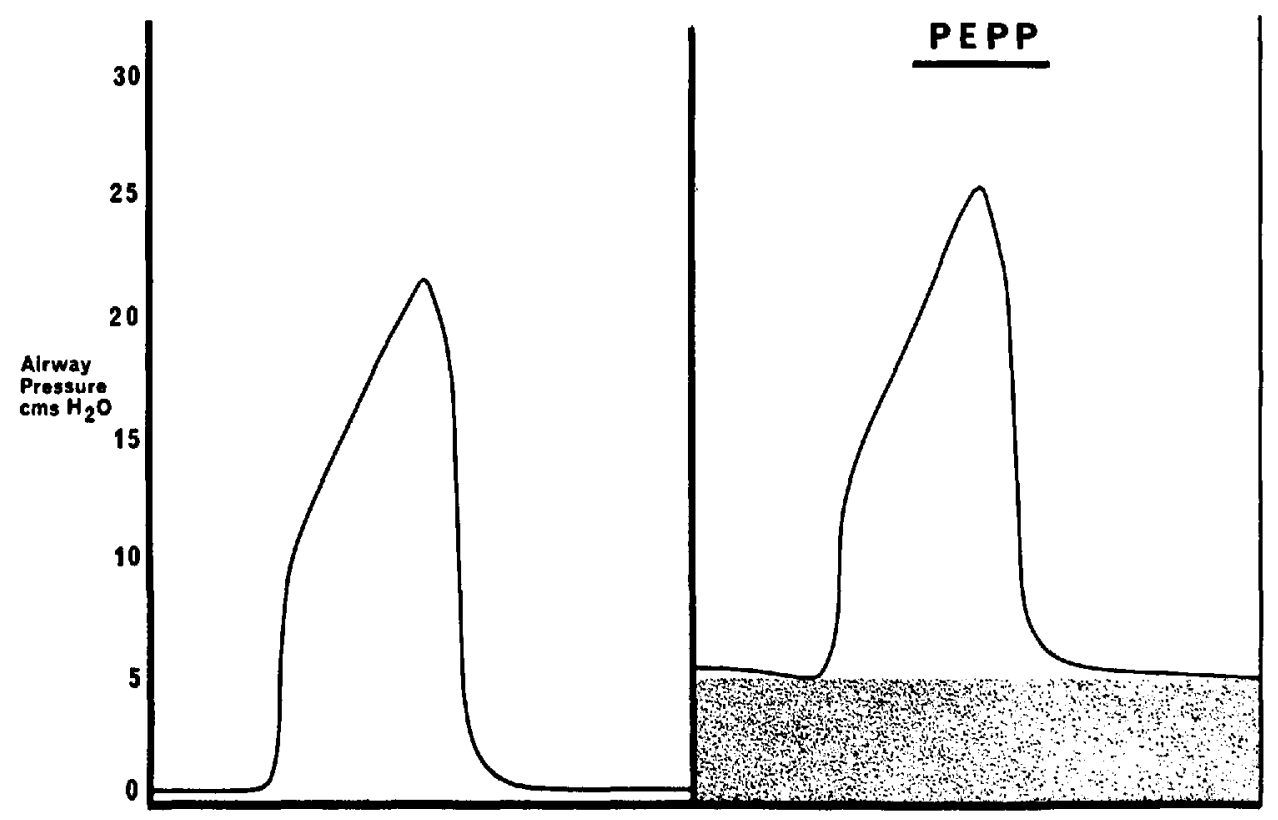

OHIO 560

Frgune 1. On left, tracheal pressure recorded during artificial ventilation with Ohio 560 ventilator. On right, similar recording with $5 \mathrm{~cm} \mathrm{H}_{2} \mathrm{O}$ positive expiratory pressure plateau.

was used, PEPP was applied by submerging the expiratory line below water. ${ }^{*}$ Inflating pressure was monitored continuously at the airway.

After one hour of ventilation without PEPP, gas exchange, cardiac output, and FRC were measured. Ventilator settings were not changed except that the PEPP of $5 \mathrm{~cm} \mathrm{H} \mathrm{H}_{2} \mathrm{O}$ was applied for one hour; a second set of measurements was then made. PEPP was removed and a third set of values obtained after one more hour. All patients lay supine. Tracheal suction was carried out before the study and immediately after each set of measurements.

Cardiac output was measured with a dye dilution technique using indocyanine green injected into the superior vena cava. Withdrawal was made from a femoral artery through an indwelling arterial line and a Waters cuvette-densitometer sys-

TABLE I

\begin{tabular}{|c|c|c|c|c|}
\hline Patient & Age & Sex & Weight $(\mathrm{kg})$ & Diagnosis \\
\hline 1 & 40 & $\mathrm{~F}$ & 45 & \multirow{3}{*}{$\begin{array}{l}\text { bronchial carcinoma, penumonectomy, } \\
\text { aspiration pneumonitis } \\
\text { varicella penumonia } \\
\text { pneumonia, coronary artery disease } \\
\text { bronchial carcinoma, pneumonectomy } \\
\text { pneumonia, myocardial infarction } \\
\text { aspiration pneumonitis, hypoxic } \\
\text { cardiac arrest }\end{array}$} \\
\hline $\begin{array}{l}2 \\
3 \\
4\end{array}$ & $\begin{array}{l}45 \\
67 \\
62\end{array}$ & $\begin{array}{l}\mathrm{F} \\
\mathrm{M} \\
\mathrm{M}\end{array}$ & $\begin{array}{l}55 \\
64 \\
64\end{array}$ & \\
\hline $\mathbf{5}$ & 60 & M & 66 & \\
\hline
\end{tabular}

'Since this study, the mal has been modified and provision has been made for applying PEPP. 
tem. Direct readout of cardiac output was obtained from a Waters co4 Cardiac Output Computer, calibrated for each patient. Each value of cardiac output reported is the mean of duplicate determinations.

FRC was measured by the helium dilution technique modified for use with artificial ventilation. ${ }^{14}$ The patient was connected by a two-way tap either to the ventilator or to the helium filled measuring circuit. This arrangement enabled circuits to be switched rapidly at end expiration and enabled the resting lung volume maintained by the pressure hold to be measured.

By incorporating an efficient one-way valve into the ventilating circuit, true expired gas could be collected without contamination by gas compressed in the ventilator tubing. When PEPP was in use, an additional mushroom valve on the expiratory port (pressurized from the ventilator circuit) was required to maintain the pressure hold on the lungs. Expired gas was collected in a Douglas bag over a period of five minutes, and during this time inspired gas was sampled and arterial blood was drawn. Gas volumes were measured with a calibrated dry gas meter and corrected to BTPS. Mixed expired $\mathrm{CO}_{2}$ concentration was measured using an infrared analyser (Beckman/Spinko LB2). A Beckman oxygen analyser (model E2) was used to determine inspired and expired oxygen concentrations. Arterial blood gas values were measured at $37^{\circ} \mathrm{C}$ with an Instrumentation Laboratories $\mathrm{pH} /$ gas analyser. Corrections to body temperature were made. Alveolar values for oxygen and carbon dioxide were calculated using the measured values for inspired gas, mixed expired gas, and tidal volume, and an assumed value for anatomical dead space based on body weight $(2.2 \mathrm{ml} / \mathrm{kg})$. Necessary adjustments to anatomical dead space for intubation, tracheostomy, and mechanical dead space were made. Arterial to alveolar tension gradients for both oxygen and carbon dioxide were derived and were used as a measure of the efficiency of pulmonary gas exchange.

\section{Results and Discussion}

The results are tabulated in Table II and appear graphically in Figures 2 to 6 . Improvement in gas exchange following the application of PEPP is shown by the rise in arterial oxygen tension and by the fall in alveolar to arterial gradients for both oxygen and carbon dioxide. This is accompanied by a rise in Frc. The opposite trend is shown in each parameter following the removal of PEPP. A significant negative finding is the absence of change in cardiac output with PEPP.

Because all patients were being ventilated with 100 per cent oxygen the fall in oxygen gradients is indicative of a reduction of wasted perfusion. Four patients with oxygen gradients of over $550 \mathrm{~mm} \mathrm{Hg}$ (a grave prognostic sign) showed a significant reduction with the application of PEPP. If this change in wasted perfusion is expressed as percentage shunt, calculation from our data reveals a reduction of up to 13 per cent.

The fall in carbon dioxide gradients indicates that PEPP resulted in a significant reduction in wasted ventilation. This is evidence that the maintenance of expiratory pressure does not result in over-expansion of already ventilated lung units. If this were occurring a rise and not a fall in carbon dioxide gradients would have been observed.

A surprising feature of the results is the lack of change in cardiac output with 


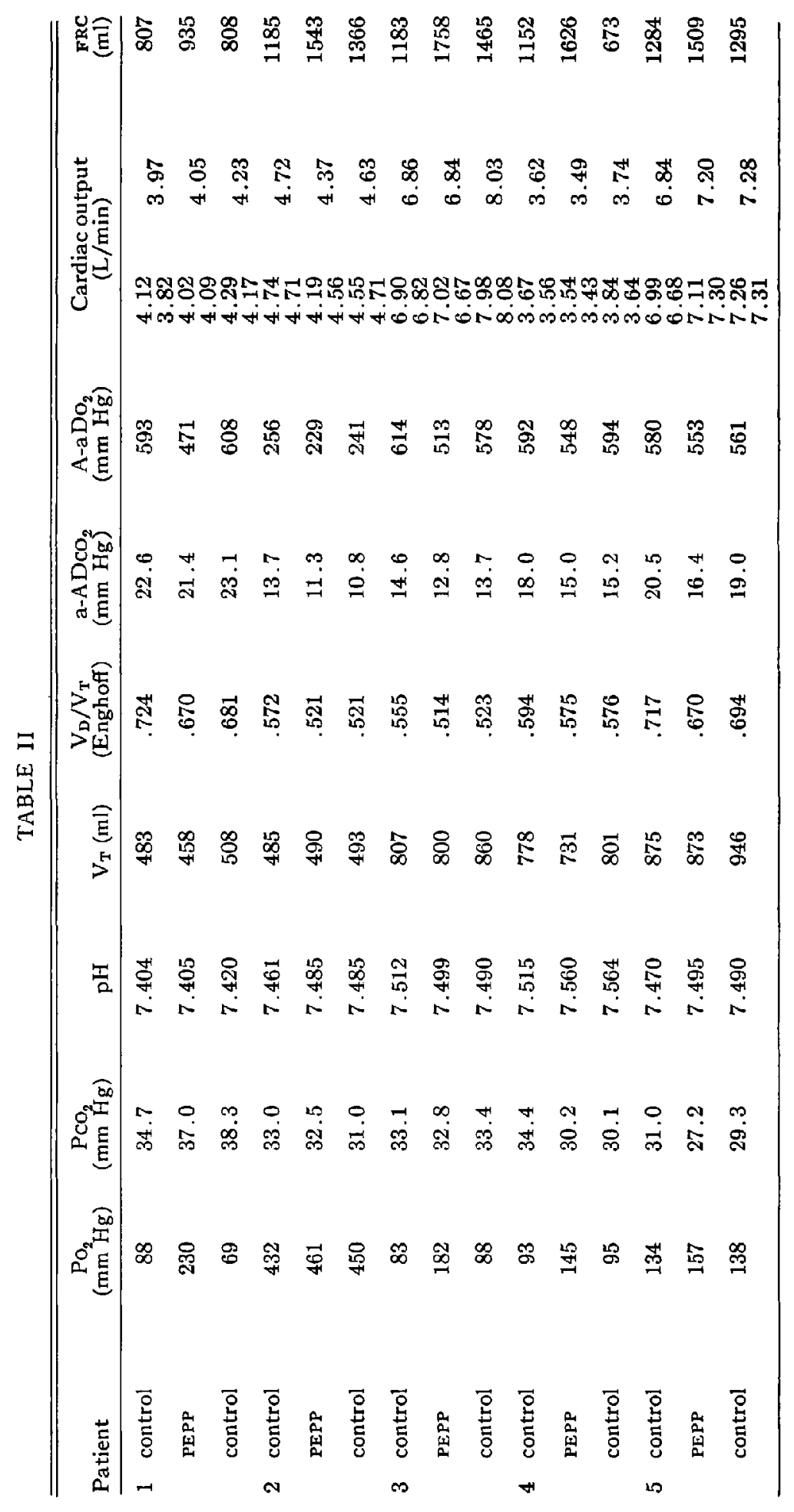




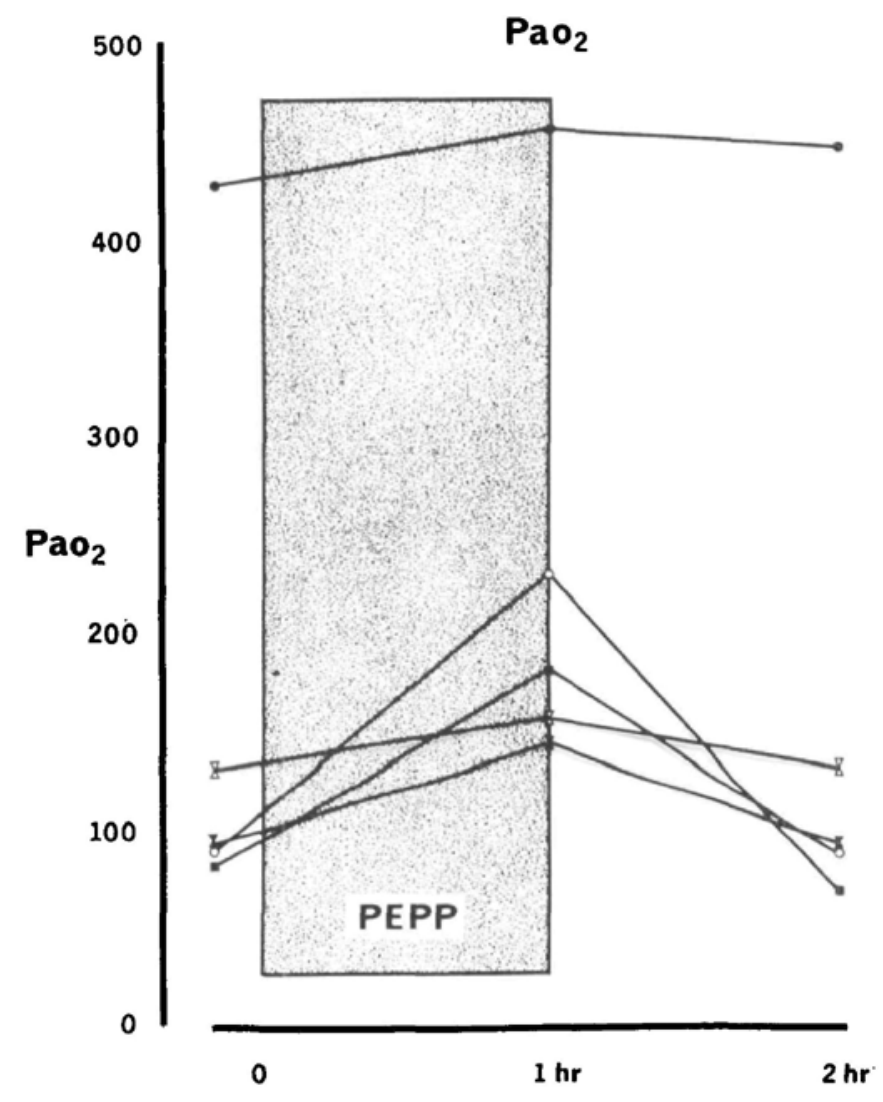

Figure 2. Changes in arterial oxygen tension with the use of PEPP.

PEPP. In view of the fact that three of these patients might be expected to have reduced cardiac reserves, this lack of change assumes even greater therapeutic importance. The one cardiac output which showed a rise after removal of PEPP was associated with a rise in body temperature and an increase in oxygen consumption. Although no change in cardiac output was found after one hour of PEPP, the transient changes immediately following its application needed to be examined. Therefore, serial outputs were measured in two patients. No significant change was observed.

In explanation of the improvement in gas exchange in the absence of changes in cardiac output, we believe that the application of PEPP is instrumental in expanding and ventilating previously non-ventilated lung units. Evidence that this does occur is provided by the observed increases in FRC.

The function of consolidated lung units will not be improved with PEPP, but the efficiency of gas exchange in the remaining lung units can be improved. The large pressures needed to open collapsed alveoli are much greater than those needed to open collapsed airways. Opening pressures for closed airways are likely to occur during the inspiratory cycle. The expiratory pressure-hold will 


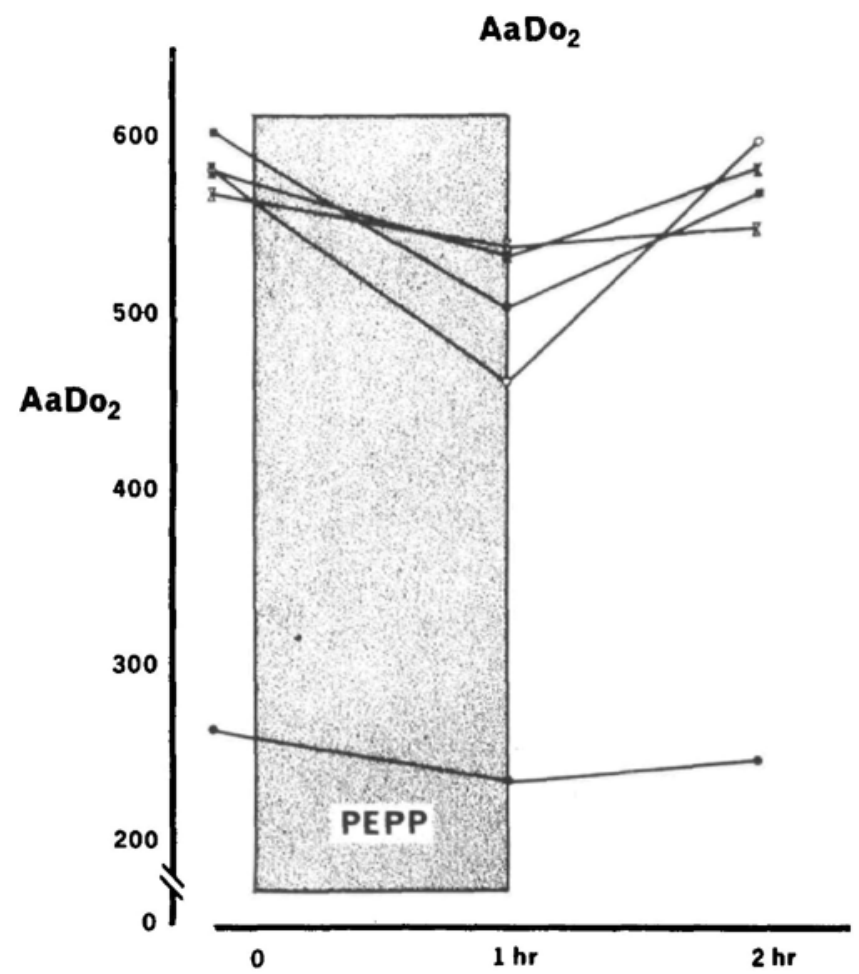

Figure 3. Changes in alveolar-arterial oxygen gradients with the use of PEPP.

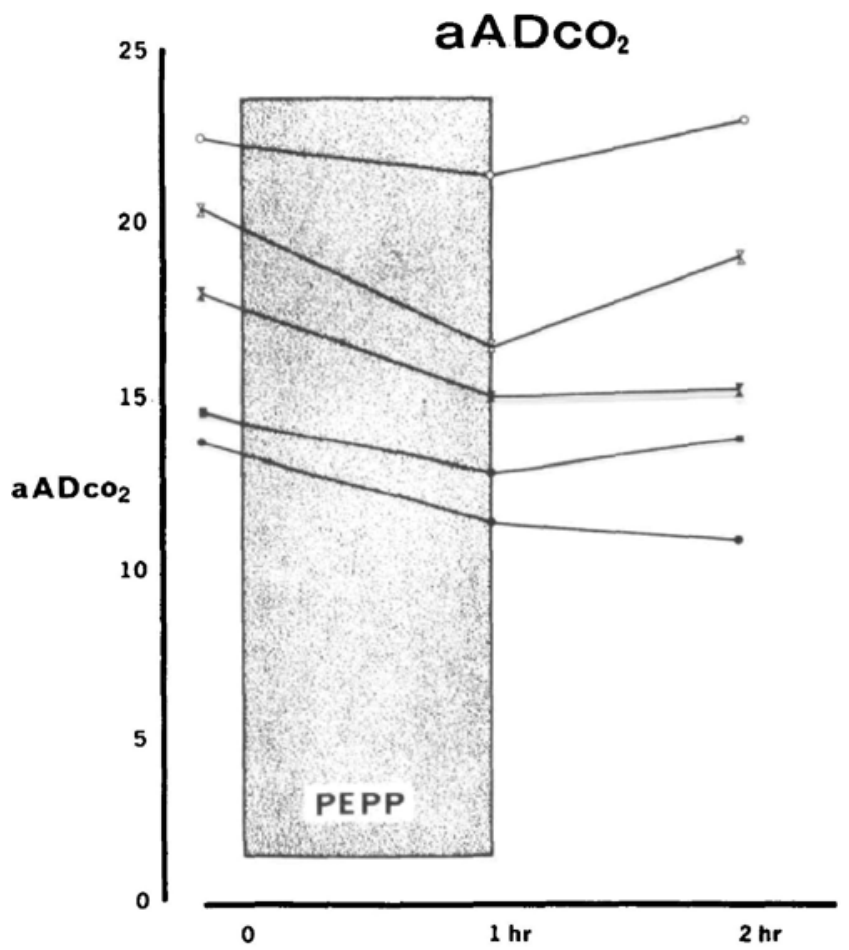

FIgure 4. Changes in arterial-alveolar carbon dioxide gradients with the use of PEPP. 


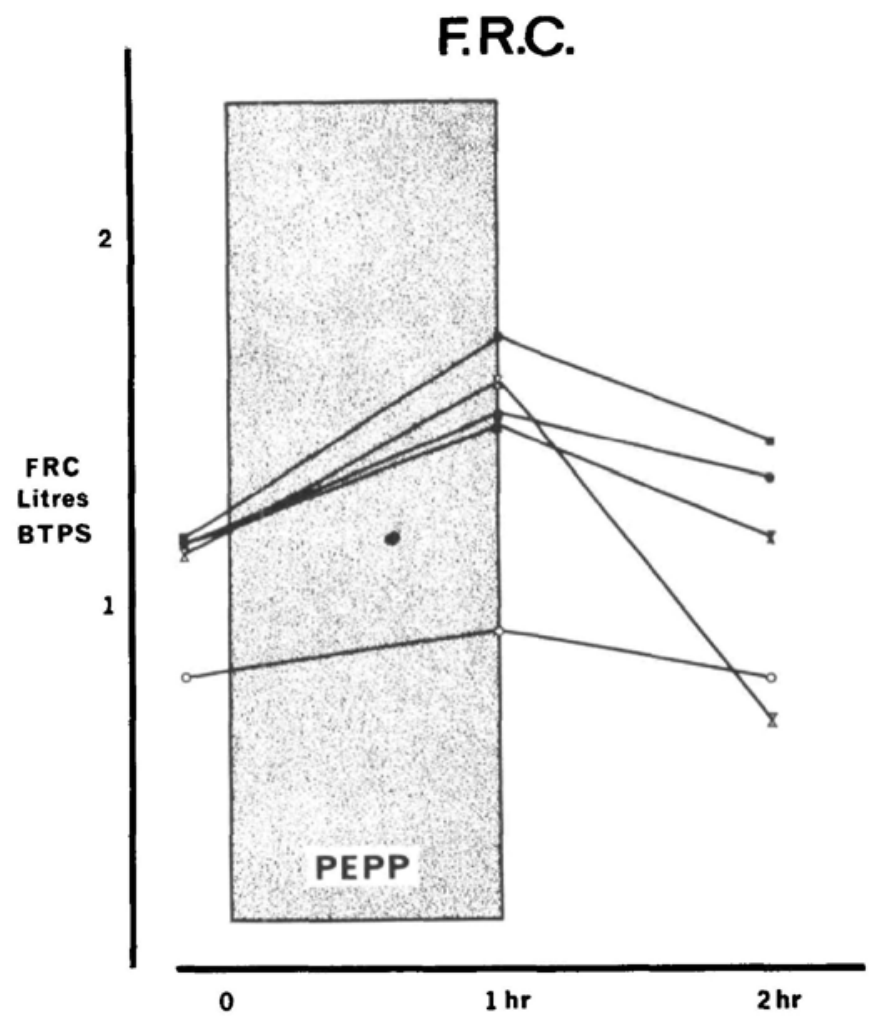

Figure 5. Changes in FRC with the use of PEPP.

function to prevent airway collapse during expiration. The pressure required for this is relatively small. This is best seen by referring to Figure 7 , which represents a static pressure-volume curve (a compliance curve) of a lung or lung unit. At low volumes on the flat part of the curve to the left, changes in transpulmonary pressure cause no change in volume since airways are closed. It is not until the transpulmonary pressures become positive that the opening pressure of the airway is reached and ventilation can occur. By the application of a maintained positive pressure, the transpulmonary pressure is increased and all lung units are moved to the right of their previous position on their pressure volume curve. Those regions at low volume with airway closure may be shifted sufficiently far to the right to maintain patent airways throughout the respiratory cycle. It is in this way that the expiratory pressure hold will operate to improve pulmonary function.

Transpulmonary pressure is not uniform, due to the effect of gravity on the lung. Pressures are maximal at the uppermost part of the lung and minimal at the most dependent part. The magnitude of the pressure gradient is related to the lung density. ${ }^{15,16}$ If the lung becomes heavier from consolidation, congestion, contusion or oedema-that is, if lung density increases, the transpulmonary pressure gradient increases and transpulmonary pressures may be negative throughout the respiratory cycle in the dependent parts of the lung. If this happens, airway closure occurs. Therefore, it is more likely that airway closure will occur in patients 


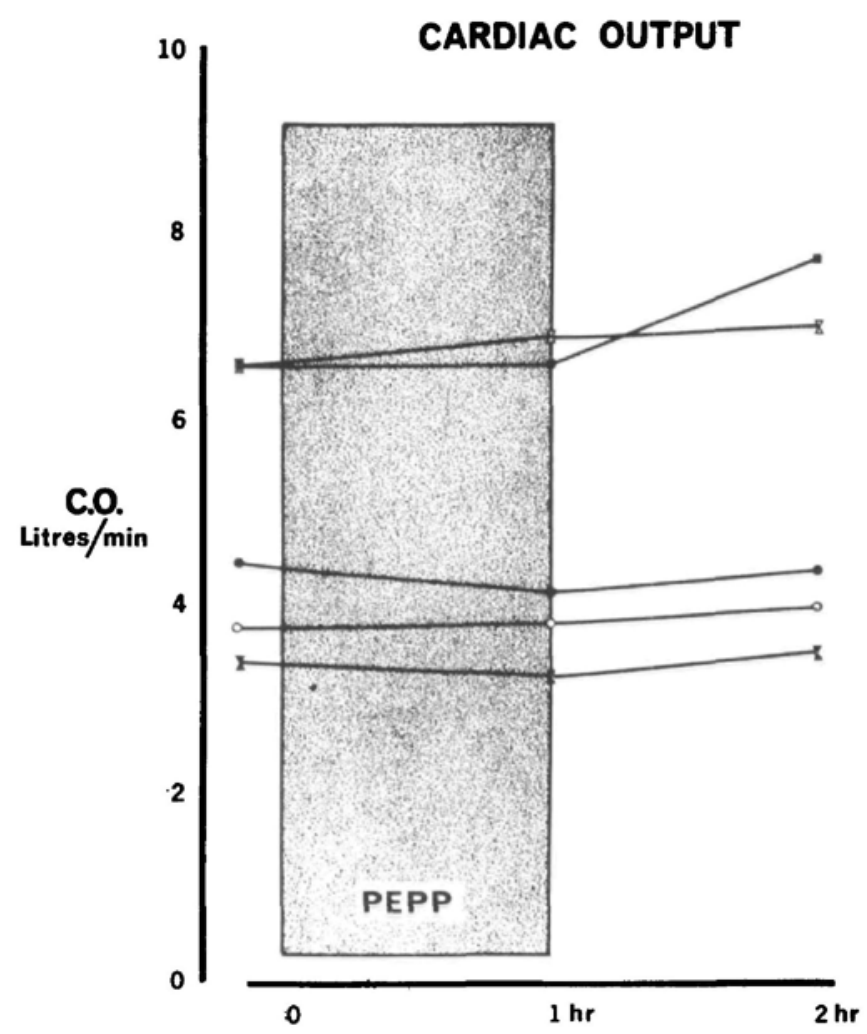

Figure 6. Changes in cardiac output with the use of PEPP.

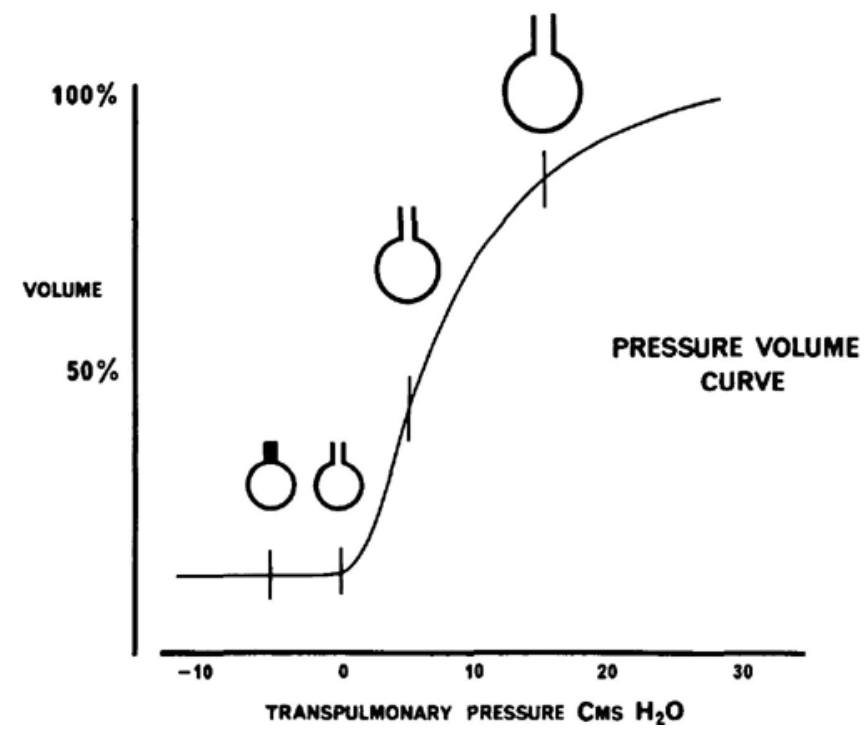

Figure 7. Static expiratory pressure-volume curve of a lung unit. 
with heavy lungs. This will apply to most patients with pulmonary disease suffciently severe to require assisted ventilation. Such patients will benefit from the application of a continuous expiratory pressure sufficient to maintain a positive transpulmonary pressure.

If lung mechanics are considered alone, the optimal maintained expiratory pressure should be that pressure which maintains the resting lung volume just above the closing volume. This is defined as the overall lung volume at which airway closure begins to occur. ${ }^{17}$ On the other hand, if maintained expiratory pressures are increased, cardiac output will eventually fall, and in the presence of shunts, arterial oxygen tensions will fall. If, however, the application of PEPP abolishes the majority of shunt channels, a fall in cardiac output will not be associated with a fall in arterial oxygen tension. ${ }^{3}$ The cardiovascular response will depend on the interplay of blood volume, venous tone, and myocardial function. The interrelationship of lung mechanics and cardiovascular response will dictate both the optimal level and the ultimate clinical limitation of PEPP. That there is often sufficient therapeutic leeway is evidenced by the beneficial results in our patients, all of whom were critically ill, and by the reported results in patients following cardiac surgery. ${ }^{11}$ The response of any particular patient should not be assumed, and careful monitoring is mandatory. Airway pressure should be measured, and serial arterial oxygen tensions will give some index of the overall response to PEPP.

The place of PEPP in routine therapy is as yet undefined, but from our experience, we propose two indications. Firstly, in patients with oxygen gradients over $550 \mathrm{~mm} \mathrm{Hg}$ PEPP may be the only means by which arterial oxygen tensions can be raised. Thus, the first indication is life saving-the prevention of hypoxia in desperate situations. Secondly, on a longer term basis, PEPP will enable acceptable arterial oxygen tensions to be maintained with lower inspired oxygen levels. Thus the second clear-cut indication is the prevention of pulmonary oxygen toxicity. We believe that a positive pressure plateau during expiration is a most important feature in the definition of the optimum pattern of ventilation. It is anticipated that in the future this feature of the ventilatory wave form will be far more generally applied in the management of patients receiving artificial ventilation. At present the number of ventilators with which PEPP can be conveniently applied is limited, but this factor should not be responsible for restricting the use of a valuable form of therapy.

\section{SUMMARY}

The effect of a positive expiratory pressure plateau (PEPP) on gas exchange, cardiac output, and FRC is examined in five patients in severe respiratory failure receiving artificial ventilation. Improvement in gas exchange for both oxygen and carbon dioxide without change in cardiac output is demonstrated in all cases. This is associated with an increase in resting lung volume. The mechanisms and therapeutic implication of these changes are discussed. It is suggested that this feature of the ventilatory wave form may be of considerable value in the management of severe hypoxia during respiratory failure. 


\section{RésUMÉ}

Chez cinq malades souffrant de défaillance respiratoire grave recevant une ventilation artificielle, nous avons étudié l'effet d'un plateau de pression positive à l'expiration (PEPP) sur les échanges gazeux, le débit cardiaque et la FrC. Dans tous les cas, nous avons pu démontrer une amélioration des échanges gazeux et pour l'oxygène et pour le gaz carbonique sans modification du débit cardiaque. Cela s'est accompagné d'une augmentation du volume pulmonaire au repos. Nous avons discuté les mécanismes et l'implication thérapeutique de ces modifications. Il est possible que ce facteur dans la forme du tracé ou de l'onde respiratoire puisse être de grande valeur dans le traitement de l'hypoxie prononcée au cours de la défaillance respiratoire.

\section{REFERENCES}

1. Watson, W. E. Observations on Physiological Dead Space during Intermittent Positive Pressure Respiration. Brit. J. Anaesth. 34: 502 (1962).

2. Bergman, N. A. Effect of Different Pressure Breathing Patterns on Alveolar-arterial Gradients in Dogs. J. Appl. Physiol. 18: 1049 (1963).

3. Famley, H. B. \& Blenkarn, G. D. Effect on Pulmonary Gas Exchange of Variations in Inspiratory Flow Rate during Intermittent Positive Pressure Ventilation. Brit. J. Anaesth. 38: 320 (1966).

4. Bergman, N. A. Effects of Varying Respiratory Wave Forms on Gas Exchange. Anesthesiology. 28: 391 (1967).

5. Cournand, A.; Motley, H. L.; Werko, L.; \& Richards, D. W. Physiological Studies of the Effects of Intermittent Positive Pressure Breathing on Cardiac Output in Man. Am. J. Physiol. 152: 162 (1948).

6. Finley, E. N.; Lenfant, C.; HaAb, B.; Puper, J.; \& Rahn, H. Venous Admixture in the Pulmonary Circulation of Anesthetized Dogs. J. Appl. Physiol. 15: 418 (1960).

7. Uzawa, T. \& Ashbaugh, D. G. Continuous Positive Pressure Breathing in Acute Haemorrhagic Pulmonary Oedema. J. Appl. Physiol, 26: 427 (1969).

8. Frumin, M. J.; Bergman, N. A.; Holaday, D. A.; Rackow, H.; \& Salanitre, E. Alveolar Arterial $\mathrm{O}_{2}$ Differences during Artificial Respiration in Man. J. Appl. Physiol. 14: 694 (1959).

9. Nunn, J. F.; Bergman, N. A.; \& Coleman, A. J. Factors Influencing the Arterial Oxygen Tension during Anaesthesia with Artificial Ventilation. Brit. J. Anaesth. 37: 898 (1965).

10. Cheyney, F. W.; Hornbenn, H. F.; \& Crawford, E. W. The Effects of Expiratory Resistence on the Blood Gas Tensions of Anesthetized Patients. Anesthesiology. 28: 670 (1967).

11. Hul, J. D.; ManN, F. B.; Osborin, J. J.; \& Gerbone, F. Correct Use of Respirator on Cardiac Patient after Operation. Arch. Surg. 91: 775 (1965).

12. Ashbaugh, D. G.; Bigelow, D. B.; Petry, T. L.; \& Levine, B. E. Acute Respiratory Distress in Adults. Lancet. 2: 319 (1967).

13. Adams, A. P.; Morgan, M.; Jones, B. C.; \& McCormick, P. W. A Case of Massive Aspiration of Gastric Contents during Obstetric Anaesthesia: Treatment by Tracheostomy and Prolonged Intermittent Positive Pressure Ventilation. Brit. J. Anaesth. 41: 176 (1969).

14. LAws, A. K. Effect of Induction of Anaesthesia and Muscle Paralysis on Functional Residual Capacity of the Lungs. Canad. Anaesth. Soc. J. 15: 325 (1968).

15. Kaneko, K.; Mrlic-Emmi, J.; Dolovich, M. B.; Dawson, A.; \& Bates, D. V. Regional Distribution of Ventilation and Perfusion as a Function of Body Position. J. Appl. Physiol. 21: 767 (1966).

16. Bhyan, A. C.; Mmic-Emur, J.; \& Pengelly, D. Effect of Gravity on the Distribution of Pulmonary Ventilation. J. Appl. Physiol. 21: 778 (1966).

17. Dollfuss, R. E.; Mnic-Emmi, J.; \& Bates, D. V. Regional Ventilation of the Lung Studied with Boluses of 133Xenon. Resp. Physiol. 2; 234 (1967). 